\title{
UJI AKTIVITAS TABIR SURYA PADA BEBERAPA SPESIES DARI FAMILY ZINGIBERACEAE DENGAN METODE SPEKTROFOTOMETRI
}

\author{
Fitriyanti Jumaetri Sami ${ }^{*}$, Syamsu Nur ${ }^{\star *}$, Megawati M. Martani ${ }^{\star *}$ \\ *) Sekolah Tinggi IImu Farmasi Makassar \\ ${ }^{* *}$ Akademi Farmasi kebangsaan Makassar \\ Email :fitriyantijumaetri_sami@yahoo.com.
}

\begin{abstract}
Testing activity sun screen of several species from family Zingiberaceae with a spectrophotometric method have been. Study purpose is to obtain data on the sunscreen activity of ginger extract $\underline{Z}$. officinale var. Officinale, $\underline{Z}$. officinale var. Rubrum and Zingiber zerumbet SM and their combination with the parameters of \% transmission of erythema, \% transmission of pigmentation and SPF. The method used an experimental laboratory. Evaluation of the activity of ethanol extract of $\underline{Z}$. officinale var. Officinale, $\underline{Z}$. officinale var. Rubrum and Zingiber zerumbet SM made by maceration method using $70 \%$ ethanol. The test is based on the ability of the absorb the rays ultraviolet. Research carried out by the respective concentrations of ethanol extract of $\underline{Z}$. officinale var. Officinale, $\underline{Z}$. officinale var. Rubrum and Zingiber zerumbet SM of 200 ppm , 400 ppm , 600 ppm, 800 ppm and 1000 ppm. Based on percent transmission of erythema and percent transmission of pigmentation at a concentration of 1000 ppm, respectively ethanol extract $\underline{Z}$. officinale var. Officinale, Z. officinale var. Rubrum and Zingiber zerumbet SM could be used as a sunscreen but still weak to be used as sunscreen ingredients. The result showed that combined $\underline{Z}$. officinale var. Officinale, Z. officinale var. Rubrum and Zingiber zerumbet SM at a concentration of $500 \mathrm{ppm}$ obtained percentage value of $1 \%$ transmission of erythema and 3,9\% of pigmentatied transmission and categories as sunblock with SPF value is 50 protection.
\end{abstract}

Key words : Family Zingiberaceae, Sunscreen, Spectrophotometric.

\section{PENDAHULUAN}

Indonesia merupakan negara tropis yang terletak disepanjang garis ekuator. Oleh karenanya masyarakat indonesia sangat terpajan oleh radiasi ultraviolet. Radiasi sinar ultraviolet yang terdapat secara natural pada sinar matahari merupakan suatu radiasi elektromagnetik yang merupakan salah satu bentuk energi (Utami, N, A., 2009).

Sinar matahari mempunyai efek, baik yang merugikan maupun yang menguntungkan, tergantung dari frekuensi dan lamanya sinar mengenai kulit, intensitas sinar matahari, serta sensitivitas seseorang. Walaupun berguna untuk pembentukan vitamin $D$ 
Uji aktivitas tabir surya pada beberapa spesies dari family zingiberaceae dengan metode spektrofotometri

yang sangat berguna bagi tubuh, sinar matahari dianggap faktor utama dari berbagai masalah kulit, mulai dari sunburn, pigmentasi kulit, penuaan kulit, hingga kanker kulit. Kulit yang terkena radiasi sinar UV akan berwarna lebih gelap, berkeriput, kusam, kering, timbul bercak-bercak coklat kehitaman (melasma), hingga kanker kulit. Bahkan jauh sebelum efek radiasi itu terlihat oleh mata telanjang, kulit sebenarnya sudah mengalami kerusakan (Theresia, S., 2010). Penggunaan kosmetik tabir surya dianjurkan di negara-negara yang terkena banyak sinar matahari. Fungsi tabir surya adalah untuk melindungi kulit dari radiasi ultraviolet dalam sinar matahari yang dapat menimbulkan berbagai kerusakan pada kulit, seperti penuaan dini, kekeringan, hiperpigmentasi sampai kanker kulit (Iswari, R. dan Latifa, F., 2007).

Bahan tabir surya selain diperoleh secara sintetik dapat diperoleh juga secara alami. Selain ekonomis, keunggulan terletak pada bahan dasarnya yang bersifat alami, oleh karena itu penting dilakukan suatu penelitian untuk mencari senyawa aktif yang berasal dari alam yang dapat berguna sebagai tabir surya (Agromedia, 2008).
Family Zingiberaceae diantaranya yaitu jahe putih besar ( $Z$. officinale var. officinale), jahe merah (Z. officinale var. rubrum), dan lempuyang gajah (Zingiber zerumbet SM). Komponen utama dari jahe segar adalah senyawa homolog fenolik keton yang dikenal sebagai gingerol. Rasa pedas dari jahe segar berasal dari kelompok senyawa gingerol, yaitu senyawa turunan fenol (Hernani., Winarti, C., 2011). Senyawa [6]gingerol telah dibuktikan sangat efektif untuk mencegah sinar ultra violet $B$ (UVB) dan bisa untuk mencegah kerusakan kulit (Ali et al. 2008). Kandungan gingerol jahe merah lebih tinggi dibanding jahe lainnya (Rehman et al. 2011). Rimpang lempuyang gajah mengandung alkaloid, saponin, flavonoida, polifenol dan minyak atsiri (Hutabarat, R, S., 2012). Flavonoid adalah suatu kelompok senyawa fenol yang potensial sebagai antioksidan dan memiliki bioaktifitas sebagai obat. Senyawa kimia (flavonoid) yang diduga dapat bekerja sebagai bahan aktif tabir surya. Flavonoid merupakan antioksidan yang kuat dan juga sebagai pengikat ion logam yang diduga mampu mencegah efek bahaya dari sinar UV atau setidaknya mampu mengurangi kerusakan kulit (Mokodompit, N, A, dkk, 2013). 
Uji aktivitas tabir surya pada beberapa spesies dari family zingiberaceae dengan metode spektrofotometri

Aktivitas sebagai tabir surya secara in vitro dapat ditentukan dengan mengukur \% transmisi eritema, \% transmisi pigmentasi, serta nilai sun protection factor (SPF) secara spektrofotometri (Wilkinson dan Moore, 1982). Sunblock (sediaan yang dapat menyerap hampir semua sinar UV-B dan sinar UV-A) apabila memiliki persentase transmisi eritema $1 \%$ dan persentase transmisi pigmentasi 340\%. Jika persentase transmisi eritema 6-18\% dan persentase transmisi pigmentasi 45-86\% dikategorikan sebagai Suntan atau dapat dikatakan suatu bahan yang menyerap sebagian besar sinar UV-B dan menyerap sedikit sinar UV-A (Cumpelik, 1972). Berdasarkan Wasitaatmadja (1997) kemampuan menahan cahaya ultraviolet dari tabir surya dinilai dalam faktor proteksi cahaya (Sun Protection Factor/SPF) yaitu perbandingan antara dosis minimal untuk menimbulkan eritema pada kulit terolesi tabir surya dengan yang tidak.

Berdasarkan latar belakang di atas maka timbul permasalahan apakah ekstrak rimpang jahe putih besar, jahe merah dan lempuyang gajah dapat digunakan sebagai bahan tabir surya dengan parameter penentuan persentase transmisi eritema, persentase transmisi pigmentasi, dan SPF. Adapun manfaat dari penelitian ini adalah memberikan informasi dan menambah wawasan kepada peneliti untuk mengetahui potensi dari jahe putih besar, jahe merah dan lempuyang gajah sebagai bahan tabir surya. Tujuan penelitian ini adalah untuk memperoleh data terhadap aktivitas tabir surya dari masing-masing ekstrak jahe putih besar, jahe merah dan lempuyang gajah serta kombinasi ketiganya dengan parameter persentase transmisi eritema, persentase transmisi pigmentasi, dan SPF.

\section{METODE PENELITIAN}

\section{Alat dan Bahan yang digunakan}

Alat yang digunakan yaitu bejana alat maserasi, alat-alat gelas, batang pengaduk, cawan porselin, rotari evaporator, UV Spectrophotometer (Shimadzu, UV1800), timbangan analitik ( Mettler Toledo).

Bahan-bahan yang digunakan yaitu air suling, rimpang jahe putih besar ( $Z$. officinale var. officinale), jahe merah ( $Z$. officinale var. rubrum), lempuyang gajah (Zingiber zerumbet SM), etanol $70 \%$, etanol absolut P.a (Pro analys). 
Uji aktivitas tabir surya pada beberapa spesies dari family zingiberaceae dengan metode spektrofotometri

\section{Prosedur kerja}

\section{Pengambilan sampel}

Sampel rimpang jahe putih besar dan jahe merah diambil dari Kabupaten Maros Prov. Sulawesi Selatan. Sampel lempuyang gajah di ambil dari pasar Beringharjo Jalan Jenderal Ahmad Yani nomor 16, Yogyakarta.

\section{Pengolahan sampel}

Pembuatan ekstrak jahe putih besar, jahe merah dan lempuyang gajah, dilakukan dengan cara sebagai berikut, masing-masing rimpang dicuci bersih, kemudian diiris tipis-tipis, dikeringkan sehingga menjadi simplisia, dan ditimbang lalu dihaluskan dengan blender sampai menjadi serbuk berukuran 60 mesh. Kemudian masing-masing sampel jahe putih besar, jahe merah dan lempuyang gajah ditimbang, selanjutnya sampel siap di ekstraksi.

\section{Pembuatan Ekstrak}

200 g Sampel serbuk rimpang jahe putih besar, jahe merah dan lempuyang gajah masing-masing diekstraksi dengan cara dimaserasi selama $3 \quad$ x 24 jam dengan menggunakan pelarut etanol $70 \%$ sambil sesekali diaduk dan terlindungi dari paparan sinar matahari langsung. Ekstrak yang diperoleh dikumpulkan kemudian disaring dan diuapkan hingga diperoleh ekstrak kental. Ekstrak kental yang diperoleh dimasukkan dalam wadah yang sesuai kemudian ditimbang berat ekstrak.

Penentuan Persentase Transmisi Eritema, Persentasi Transmisi Pigmentasi dan SPF

Disiapkan dengan cara menimbang masing-masing $50 \mathrm{mg}$ ekstrak etanol jahe putih besar, jahe merah dan lempuyang gajah dan dilarutkan dengan etanol absolut, dimasukan kedalam labu takar, dihomogenkan, volume akhir dicukupkan dengan etanol hingga 50,0 $\mathrm{mL}$ (1000 ppm). Larutan stok masingmasing dipipet $2,0 \mathrm{~mL}, 4,0 \mathrm{~mL}, 6,0 \mathrm{~mL}$, dan $8,0 \mathrm{~mL}$. Kemudian dicukupkan volumenya sampai $10,0 \mathrm{~mL}$ dengan etanol absolut sehingga diperoleh variasi pelarut dengan konsentrasi 200 ppm, 400 ppm, 600 ppm, 800 ppm. Masing-masing konsentrasi 200 ppm, 400 ppm, 600 ppm, 800 ppm dan 1000 ppm diukur serapannya dengan menggunakan spektrofotometer UV pada panjang gelombang yang dapat menimbulkan eritema dan pigmentasi yaitu $292,5 \mathrm{~nm}-372,5 \mathrm{~nm}$.

Penentuan persentasi transmisi eritema/pigmentasi dan SPF kombinasi ekstrak ekstrak etanol jahe putih besar, jahe merah dan lempuyang gajah dengan cara 
Uji aktivitas tabir surya pada beberapa spesies dari family zingiberaceae dengan metode spektrofotometri

menimbang $50 \mathrm{mg}$ ekstrak etanol jahe putih besar, jahe merah dan lempuyang gajah dan dilarutkan dengan etanol absolut, dimasukan kedalam labu takar, dihomogenkan, volume akhir dicukupkan dengan etanol hingga $100 \mathrm{~mL}$ (500 ppm) kemudian diukur serapannya dengan menggunakan spektrofotometer pada panjang gelombang yang dapat menimbulkan eritema dan pigmentasi yaitu $292,5 \mathrm{~nm}-372,5 \mathrm{~nm}$.

\section{Analisis Data}

Pengumpulan dan pengolahan data mencakup parameter penentuan persentase transmisi eritema, persentase transmisi pigmentasi dan SPF. Berdasarkan nilai serapan (A) yang diperoleh, maka transmisi $(\mathrm{T})$ dihitung menggunakan rumus:

Keterangan :

$$
A=-\log T
$$

A = Serapan

$\mathrm{T}=$ Transmisi

Transmisi eritema (Te) dihitung mengguanakan rumus:

Keterangan :

$$
T e=T \times F e
$$

$\mathrm{Te}=$ Transmisi eritema

$\mathrm{Fe}=$ Fluks eritema

Dimana $\mathrm{Fe}$ adalah fluks eritema yang nilainya pada panjang gelombang tertentu. Banyak fluks eritema yang diteruskan oleh tabir surya (Ee) dihitung dengan rumus:

$$
E e=\sum(T \times F e)
$$

Keterangan :

$\mathrm{Ee}$ = Banyaknya fluks eritema yang diteruskan oleh tabir surya.

Sedangkan \% transmisi eritema dihitung menggunakan rumus:

$\%$ Transmisi Eritema $=\frac{E e}{\sum F e}=\frac{\sum(T \times F e)}{\sum F e}$

Transmisi Pigmentasi (Tp) dihitung menggunakan rumus:

$$
T p=T \times F p
$$

Keterangan :

$\mathrm{Tp}=$ Transmisi pigmentasi

$\mathrm{T} \quad=$ Transmisi

$\mathrm{Fp} \quad=$ Fluks pigmentasi

Dimana $\mathrm{Fp}$ adalah fluks pigmentasi yang nilainya pada panjang gelombang tertentu. Banyaknya fluks pigmentasi yang diteruskan oleh tabir surya (Ep) dihitung dengan rumus:

$$
E p=\sum(T x F p)
$$

Keterangan :

$$
\begin{gathered}
\mathrm{Ep}= \\
\begin{array}{c}
\text { Banyaknya fluks pigmentasi yang } \\
\text { diteruskan oleh tabir surya. }
\end{array}
\end{gathered}
$$

Sedangkan \% transmisi pigmentasi dihitung menggunakan rumus:

$\%$ Transmisi Pigmentasi
$=\frac{E p}{\Sigma F p}=\frac{\Sigma(T X F p)}{\Sigma F p}$
Nilai SPF dihitung menggunakan rumus :

\begin{tabular}{ll|}
\hline AUC & $=\frac{A a+A b}{2} \times\left(\mathrm{dP}_{\mathrm{a}-\mathrm{b}}\right)$ \\
Log SPF & $=\frac{A U C}{\lambda n-\lambda 1} \times \mathrm{FP}$
\end{tabular}


Uji aktivitas tabir surya pada beberapa spesies dari family zingiberaceae dengan metode spektrofotometri

Keterangan :

$\mathrm{AUC}=$ Area Under Curve

$\mathrm{A}_{\mathrm{a}} \quad=$ Absorban panjang gelombang a nm

$A_{b} \quad=$ Panjang gelombang pada $b$ $\mathrm{nm}$

$\mathrm{dP}_{\mathrm{a}-\mathrm{b}}=$ Selisih panjang gelombang $\mathrm{a}$ dan b

SPF $=$ Sun Protection Factor (Faktor proteksi cahaya)

$\lambda \mathrm{n} \quad=$ Panjang gelombang terbesar

$\lambda_{1} \quad=$ Panjang gelombang terkecil

$\mathrm{FP}=$ Faktor pengenceran ( $\mathrm{FP}=1$ untuk ekstrak)

\section{HASIL PENELITIAN}

Hasil perhitungan \% transmisi eritema dan \% transmisi pigmentasi serta SPF dari masing-masing ekstrak etanol rimpang jahe putih besar, jahe merah dan lempuyang gajah pada konsentrasi 200, 400, 600, 800 dan 1000 ppm dapat dilihat pada tabel dibawah ini :

Tabel 1. Perhitungan \% transmisi dan pigmentasi dari ekstrak etanol rimpang jahe putih besar, jahe merah dan lempuyang gajah.

\begin{tabular}{|c|c|c|c|c|}
\hline \multirow{2}{*}{$\begin{array}{c}\text { Family } \\
\text { Zingiberaceae }\end{array}$} & \multirow{2}{*}{$\begin{array}{l}\text { Konsentrasi } \\
(\mathrm{ppm})\end{array}$} & \multicolumn{2}{|c|}{ \% Transmisi } & \multirow{2}{*}{$\begin{array}{l}\text { Kategori } \\
\text { penilaian }\end{array}$} \\
\hline & & Eritema & Pigmentasi & \\
\hline \multirow{5}{*}{ Jahe Putih Besar } & 200 & 41,45 & 52,31 & - \\
\hline & 400 & 36,15 & 49,23 & - \\
\hline & 600 & 27,87 & 38,38 & - \\
\hline & 800 & 16,51 & 26,00 & - \\
\hline & 1000 & 10,23 & 16,19 & Sunblock lemah \\
\hline \multirow{5}{*}{ Jahe Merah } & 200 & 52,47 & 62,47 & - \\
\hline & 400 & 26,95 & 36,52 & - \\
\hline & 600 & 11,11 & 19,16 & - \\
\hline & 800 & 5,39 & 10,89 & - \\
\hline & 1000 & 2,90 & 5,30 & Sunblock lemah \\
\hline \multirow{5}{*}{ Lempuyang Gajah } & 200 & 65,93 & 70,27 & - \\
\hline & 400 & 46,10 & 50,68 & - \\
\hline & 600 & 26,99 & 35,98 & - \\
\hline & 800 & 21,33 & 24,08 & - \\
\hline & 1000 & 14,10 & 17,46 & Sunblock lemah \\
\hline
\end{tabular}

Tabel 2. Hasil perhitungan SPF dari ekstrak etanol rimpang jahe putih besar, jahe merah dan lempuyang gajah.

\begin{tabular}{cccc}
\hline Family Zingiberaceae & Konsentrasi (ppm) & Nilai SPF & Kategori Penilaian \\
\hline & 200 & 2,04 & Proteksi minimal \\
Jahe Putih Besar & 400 & 2,21 & Proteksi minimal \\
& 600 & 2,86 & Proteksi minimal \\
& 800 & 4,41 & Proteksi sedang \\
& 1000 & 7,21 & Proteksi ekstra \\
\hline \multirow{5}{*}{ Jahe Merah } & 200 & 1,68 & - \\
& 400 & 3,04 & Proteksi sedang \\
& 600 & 6,56 & Proteksi ekstra \\
& 800 & 11,72 & Proteksi maksimal \\
& 1000 & 24,49 & Proteksi ultra \\
\hline \multirow{3}{*}{ Lempuyang Gajah } & 200 & 1,43 & - \\
& 400 & 1,93 & - \\
& 600 & 2,83 & Proteksi minimal \\
& 800 & 4,02 & Proteksi sedang \\
& 1000 & 5,92 & Proteksi sedang \\
\hline
\end{tabular}


Uji aktivitas tabir surya pada beberapa spesies dari family zingiberaceae dengan metode spektrofotometri

Tabel 3. Hasil perhitungan \% Transmisi Eritema, \% Transmisi Pigmentasi, dan SPF dari kombinasi ekstrak etanol rimpang jahe putih besar, jahe merah dan lempuyang gajah

\begin{tabular}{cccc}
\hline Family zingiberaceae & Konsentrasi (ppm) & Pengukuran tabir surya & Kategori penilaian \\
\hline Kombinasi ekstrak jahe & & $\%$ TE $: 1$ & Total blok \\
putih besar, jahe merah & $500 \mathrm{ppm}$ & $\%$ TP : 3,9 & Total blok \\
dan lempuyang gajah & & SPF $: 50$ & Proteksi Ultra \\
\hline
\end{tabular}

Tabel 4. Klasifikasi Produk Suntan Berdasarkan \% Eritema dan Pigmentasi Serta Keefektifan Sediaan Tabir Surya Berdasarkan Nilai SPF

\begin{tabular}{|c|c|}
\hline $\begin{array}{c}\text { Range transmisi eritema/pigmentasi (\%) \& } \\
\text { klasifikasinya }\end{array}$ & Nilai SPF \& Kategori Proteksi Tabir Surya \\
\hline \%TE < 1,0 dan \%TP 3 - 40: Total block & 2-4: Proteksi minimal \\
\hline \%TE 1-6 dan \%TP 42 - 86: Perlindungan ekstra & 4-6: Proteksi sedang \\
\hline \%TE $6-12$ dan \%TP 45 - 86: Suntan regular & 6-8: Proteksi ekstra \\
\hline \%TE 10 - 18 dan \%TP 45 - 86: Tanning cepat & 8-15: Proteksi maksimal \\
\hline- & $>15:$ Proteksi ultra \\
\hline
\end{tabular}

\section{PEMBAHASAN}

Pada penelitian ini yaitu menguji aktivitas tabir surya family zingiberaceae (jahe putih besar, jahe merah dan lempuyang gajah) yang dikerjakan menggunakan metode spektrofotometri dengan parameter nilai persentase transmisi eritema dan persentase transmisi pigmentasi serta SPF. Terlebih dahulu masing-masing jahe putih besar, jahe merah dan lempuyang gajah yang sudah menjadi simplisia diekstraksi dengan metode maserasi menggunakan pelarut etanol $70 \%$ karena selektif, tidak beracun, netral, absorbsinya baik, dan tidak mudah ditumbuhi mikroba. Proses maserasi sampel jahe putih besar, jahe merah dan lempuyang gajah menghasilkan estrak cair yang kemudian diuapkan hingga diperoleh ekstrak kental dengan warna ekstrak masing-masing berwarna coklat, coklat kemerahan dan coklat muda.

Proses selanjutnya adalah penentuan persentase transmisi eritema dan persentase transmisi pigmentasi serta SPF menggunakan metode spektrofotometri dengan mengamati masing-masing nilai serapan larutan ekstrak jahe putih besar, jahe merah dan lempuyang gajah dengan kadar 200 ppm, 400 ppm, 600 ppm, 800 ppm, dan 1000 ppm pada panjang gelombang 292,5$372,5 \mathrm{~nm}$ dengan jarak perubahan skala pengamatan $5 \mathrm{~nm}$.

Dari data perhitungan \% transmisi eritema dan pigmentasi yang dapat dilihat pada tabel 4 terlihat bahwa masing-masing jahe putih besar, jahe merah dan lempuyang 
Uji aktivitas tabir surya pada beberapa spesies dari family zingiberaceae dengan metode spektrofotometri

gajah yang diuji mempunyai efek perlindungan terhadap radiasi sinar matahari, khususnya sinar UV-A dan UV-B. Hal ini tampak pada nilai persentase transmisi eritema dan nilai persentase transmisi pigmentasi pada konsentrasi 200 hingga 1000 ppm menurun akan tetapi efek tersebut masih lemah untuk dapat digunakan sebagai bahan tabir surya secara tunggal.

Sunblock (sediaan yang dapat menyerap hampir semua sinar UV-B dan sinar UV-A) apabila memiliki persentase transmisi eritema $1 \%$ dan persentase transmisi pigmentasi 340\% (Cumpelik, 1972). Jika persentasi transmisi eritema 6-18\% dan persentase transmisi pigmentasi 45$86 \%$ dikategorikan sebagai Suntan atau dapat dikatakan suatu bahan yang menyerap sebagian besar sinar UV-B dan menyerap sedikit sinar UV-A (Cumpelik, 1972). Semakin kecil nilai $\%$ transmisi eritema maupun pigmentasi berarti potensi tabir surya dalam melindungi kulit menjadi lebih baik.

Dari ketiga sampel dengan konsentrasi 200, 400, 600, 800 dan $1000 \mathrm{ppm}$ nilai \% transmisi eritema maupun pigmentasi paling terkecil terdapat pada konsentrasi 1000 ppm. Hasil ekstrak rimpang lempuyang gajah yang mengandung alkaloid yaitu senyawa yang diduga dapat bekerja sebagai bahan aktif tabir surya pada 1000 ppm diperoleh nilai persentase transmisi eritema $14,10 \%$ dan persentase transmisi pigmentasi $17,46 \%$, hasil menunjukan positif memiliki aktivitas tabir surya, dikategorikan sunblock lemah dan memiliki nilai SPF yang dikategorikan sebagai SPF Proteksi sedang yaitu 5,92 . Pada jahe putih besar dengan konsentrasi 1000 ppm diperoleh nilai persentase transmisi eritema $10,23 \%$ dan persentase transmisi pigmentasi $16,19 \%$ dan pada jahe merah dengan konsentrasi 1000 ppm diperoleh nilai persentase transmisi eritema 2,90\% dan persentase transmisi pigmentasi $5,30 \%$, berdasarkan data tersebut ekstrak jahe putih besar dan jahe merah pada konsentrasi 1000 ppm memiliki aktivitas tabir surya, dikategorikan sunblock lemah, namun jahe merah lebih baik dari jahe putih besar karena data persentase transmisi eritema dan pigmentasi jahe merah tidak terjadi perbedaan yang terlalu mencolok bila dibandingkan dengan data pustaka. Dapat juga dilihat berdasarkan nilai SPF untuk jahe putih yaitu 7,21 masuk dalam katekori proteksi ekstrak dan jahe merah memiliki nilai SPF 24,49, 
Uji aktivitas tabir surya pada beberapa spesies dari family zingiberaceae dengan metode spektrofotometri

termasuk dalam kategori proteksi ultra.

Hal ini Bisa disebabkan karena kandungan gingerol jahe merah lebih tinggi dibanding jahe lainnya (Rehman et al.2011).

Hasil data yang diperoleh pada konsentrasi 1000 ppm, masing-masing ekstrak etanol jahe putih besar, jahe merah dan lempuyang gajah bisa digunakan sebagai bahan tabir surya namun masih lemah untuk dapat digunakan sebagai bahan tabir surya secara tunggal, sehingga dikombinasikan jahe putih besar, jahe merah, dan lempuyang gajah pada konsentrasi 500 ppm diperoleh nilai persentase transmisi eritema $1 \%$ dan persentase transmisi pigmentasi 3,9\% dengan kategori sunblock total dan hasil perhitungan SPF 50 dengan kategori proteksi ultra.

\section{KESIMPULAN}

Berdasarkan pengujian persen transmisi eritema dan persen transmisi pigmentasi dapat disimpulkan masingmasing ekstrak etanol jahe putih besar, jahe merah dan lempuyang gajah bisa digunakan sebagai bahan tabir surya namun masih lemah untuk dapat digunakan sebagai bahan tabir surya secara tunggal sehingga dikombinasikan jahe putih besar, jahe merah, dan lempuyang gajah pada konsentrasi 500 ppm diperoleh nilai persentase transmisi eritema $1 \%$ dan persentase transmisi pigmentasi 3,9\% dengan kategori sunblock total dan hasil perhitungan SPF 50 dengan kategori proteksi ultra.

\section{DAFTAR PUSTAKA}

Ali, B.H., Blunden, M. O., Tanira, A., Nemmar. 2008. Some Phytochemical, Pharmacological And Toxicological Properties of Ginger (Zingiber Officinale Roscoe): A review of recent research. Food and Chemical Toxicology

Cumpelik, B.S., 1972. Analitical procedures and evaluation of sunscreens. Journal of The Society of Cosmetics Chemist.

Hernani., Winarti, C,. 2011. Kandungan Bahan Aktif Jahe Dan Pemanfaatannya Dalam Bidang Kesehatan. Balai Besar Penelitian Dan Pengembangan Pascapanen Pertanian, Bogor.

Hutabarat, R.S., 2012. Karakterisasi Simplisia, Isolasi MinyakAtsiri Dan Analisis Komponen MinyakAtsiri Secara Gc-Ms Dari Rimpang Lempuyang Gajah (Zingiber zerumbet Sm.). Universitas Sumatera Utara, Medan.

Iswari, R., Latifa, F,. 2007. Buku Pegangan Ilmu Pengetahuan Kosmetik. PT. Gramedia Pustaka Utama, Jakarta.

Mokodompit, N.A., Edy, J.H., Wiyono, W,. 2013. Penentuan Nilai Sun Protective Factor (Spf) Secara In Vitro Krim TabirSurya Ekstrak Etanol Kulit Alpukat. Menado: 
Uji aktivitas tabir surya pada beberapa spesies dari family zingiberaceae dengan metode spektrofotometri

Universitas Samratulangi,
Menado.

Redaksi Agromedia. 2008. Buku Pintar

Tanaman Obat. PT.Agromedia Pustaka, Jakarta.

Rehman, R., Akram, M.N., Akhtar, Q., Jabeen, T., Saeed, S.M.A., Shah, K., Ahmed, G., Shaheen. H.M. Asif. 2011. Zingiber officinale Roscoe (pharmacological activity). Journal of Medicinal Plants Research

Theresia, S,. 2010. Pengaruh Penambahan Zink Oksida (Zno) Terhadap Efektivitas Sediaan Tabir Surya Kombinasi Oksibenson Dan
Oktilmetoksisinamat Dalam Basis Vanishing Cream. Universitas Sumatera Utara, Medan

Utami, N.A., 2009. Perbedaan efek antiinflamasi kurkumin 1\% dalam vehikulum krim dan salep pada kulit mencit yang telah disinari ultraviolet. Jakarta : Universitas Indonesia.

Wasitaatmadja, S.M.,1997. Penuntun IImu Kosmetik Medik. Jakarta: Penerbit Universitas Indonesia.

Wilkinson, J.B., Moore, R.J., 1982. Harry's cosmetology (17th edition) . New york. Chemichal publishing company. 